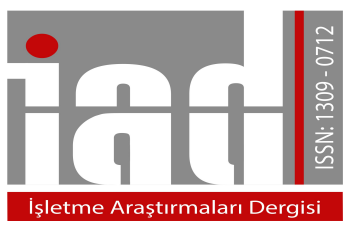

İşletme Araştırmaları Dergisi

Journal of Business Research-Turk

10/3 (2018) 471-487

Journal Of

Business Research

Turk

www.isarder.org

\title{
Sosyal Pazarlama Uygulamaları ve Marka İletişiminin Marka Güveni ve Daha Fazla Ödeme İsteği Üzerindeki Etkileri: Head \& Shoulders Markası Üzerine Bir Araştırma
}

\author{
The Effects of Social Marketing Practices and Brand Communication on \\ Brand Trust and Willingness to Pay More: A Research on the Head \& \\ Shoulders Brand
}

\author{
Erkan YILDIZ \\ Başkent Üniversitesi \\ Kazan Meslek Yüksekokulu \\ Ankara, Türkiye \\ orcid.org/0000-0002-4398-5378 \\ eryildiz@gmail.com.tr
}

\begin{abstract}
Özet
$\mathrm{Bu}$ çalışmanın amacı sosyal pazarlama uygulamaları ve marka iletişiminin marka güveni ve daha fazla ödeme isteği üzerindeki etkilerini araştırmaktır. $\mathrm{Bu}$ amaçla Ankara'da şampuan sektörüne yönelik bir araştırma yapılmıştır. 10 akademisyenden oluşan bir odak grupla; kullanılan şampuan markaları, markaların üretici firmaları ve firmaların sosyal sorumluluk projelerine yönelik nitel bir araştırma yapılmıştır. Araştırma sonucunda; Dünya, Avrupa ve Türkiye Basketbol ligindeki sponsorluklarıyla bilinen Head \& Shoulders markası ön plana çıkmıştır. Bu markayı kullanan 384 tüketiciden, kolayda örnekleme tekniğiyle, 1 Haziran - 30 Temmuz 2017 tarihleri arasında toplanan veriler, analiz edilmiştir. Veri setinin, yap1 geçerliliği doğrulayıcı faktör analiziyle, güvenilirliği cronbach alfa katsayıları ile test edilmiştir. Araştırma hipotezleri için yapısal eşitlik modellemesinden yararlanılmıştır. Araştırma sonucunda; sosyal pazarlama uygulamaları ve marka iletişiminin marka güvenini, marka güveninin de daha fazla ödeme isteğini direkt, sosyal pazarlama uygulamaları ve marka iletişiminin daha fazla ödeme isteğini marka güveni üzerinden dolaylı olarak etkilediği tespit edilmiştir. Marka güveninin açıklanma oranı \%59, daha fazla ödeme isteğinin açıklanma oranı da \%62 olarak gerçekleşmiştir.
\end{abstract}

Anahtar Kelimeler: Sosyal pazarlama uygulamaları, marka iletişimi, marka güveni, daha fazla ödeme isteği

\section{Abstract}

The purpose of this study is to investigate the effects of social marketing practices and brand communication on brand trust and the willingness to pay more. For this purpose, a study related to shampoo sector was carried out in Ankara. A qualitative research based on the shampoo brands the consumers use, the manufacturers of the 
brands and the social responsibility projects of the companies has been carried out with a focus group consisting of 10 academicians. As a result of the research; Head \& Shoulders known for its sponsorships in World, Europe and Turkey Basketball League has come to the fore. The data collected from 384 consumers using this brand between June 1st and July 30 $0^{\text {th }}, 2017$ was analyzed with convenience sampling method. The construct validity of the data set was tested by confirmatory factor analysis, its reliability was tested by cronbach alpha coefficients. Structural equation modeling has been used for research hypotheses. As a result of the research; it has been determined that social marketing practices and brand communication affect brand trust directly and brand trust affects willingness to pay more directly while social marketing practices and brand communication affect willingness to pay more indirectly over brand trust. The rate of explanation of brand trust was $59 \%$ and the rate of explanation of willingness to pay more was $62 \%$.

Key Words: Social marketing practices, brand communication, brand trust, willingness to pay more,

\section{Giriş}

Günümüz tüketicisi satın alma noktasında sahip olduğu çok fazla seçenek sayesinde markalar arasında çok farklı kriterleri baz alarak karşılaştırmalar yapabilme yetisine sahiptir. Bu durumda markalar arasındaki rekabetin daha şiddetli yaşanmasına yol açmaktadır. Özellikle ürün özellikleri ve fiyat aralıklarının birbirine çok yakın olduğu sektörlerde rekabetin çok daha yoğun hissedildiği ifade edilebilir. Bu noktada markaların, tüketicileri satın almaya ikna etme konusunda farklı pazarlama stratejileri uygulamalarının gerekli olduğu söylenebilir. Bu bağlamda, tüketicilerin nezdinde özellikle son yıllarda çok daha fazla anlam ifade eden toplumsal fayda yaratan sosyal projelere destek vererek ve bu yolla tüketicilerle iletişim kurmanın doğru bir strateji olabileceği yönünde bir öngörüde bulunulabilir.

$\mathrm{Bu}$ çalışmada şampuan sektörüne yönelik yapılan bir alan araştırmasıyla, markaların sosyal pazarlama uygulamaları ve marka iletişim yeteneklerinin markaya duyulan güvene ve tüketicilerin daha fazla ödeme yapma isteklerine olan etkileri araştırılmıştır.

\section{Literatür Analizi}

Bu bölümde araştırmanın değişkenlerine yönelik olarak yapılan yazın taraması sonuçları ifade edilmiştir.

\subsection{Sosyal Pazarlama}

Wasan ve Trippathi’ye (2014) göre sosyal pazarlama; tüketicilerin hayatlarında olumlu davranış değişikliği yapacak pazarlama faaliyetleridir. Kotler ve Andreasen'a (1996) göre de sosyal pazarlama, pazarlama faaliyetlerinin topluma sunulan fayday1 gözeterek yapılmasıdır. Weinreich'de (2007) sosyal pazarlamayı, klasik pazarlamadan farklı olarak maddi kazançlar yerine birey ve toplum çıkarının ön planda tutulması olarak betimlemiştir.

Sosyal pazarlama kavramının doğuşu, işletmelerin en fazla etik dışı davranış yapabilecekleri pazarlama uygulamalarının daha ahlaki olması gerektiği yönündeki eleştirilere dayanmaktadır. Philip Kotler ve Gerald Zaltman'ın gelen eleştirilere dayanarak pazarlama faaliyetleri kapsamına toplumsal perspektifinde eklenmesi gerekliliği savlarıyla sosyal pazarlama bir kavram olarak ele alınmaya başlamıştır (Weinrech, 2007). Andreasen (1994) göre de sosyal pazarlama, fikirlerin yanında, tavır 
ve davranışları da etkiler. Yazar ayrıca kişilerdeki tavır ve davranış değişikliklerinin gönüllülük esasına dayandığını da öne sürmüştür.

Sosyal pazarlama faaliyetlerinin odak noktasını; eğitim, sağlık, çevreyi koruma, küresel 1sınmayı önleme, hayvanları koruma gibi toplumsal yaşantı üzerinde çok büyük etkileri olan alanlar oluşturmaktadır. Bu alanların yanında diğer toplumsal meselelerde sosyal pazarlamanın ilgi alanına girmektedir (Erol, 2017; Uptown ve Thirlaway, 2014).

Sosyal pazarlama, istenen davranış biçimi ve davranış değişikliklerini zorlamak için özellikle hedef kitlenin ilgisini çeken sosyal konularda oldukça etkilidir (BeerliPalacio ve Martin-Santana, 2015). Dolayısıyla sosyal pazarlamanın insanların tutumlarını anlama konusuna dayandığı ve toplumun değer yargılarını değiştirmeye ve/veya toplumu bilgilendirmeyi amaçladığı belirtilebilir (Aydın ve Koç, 2016).

Hoek ve Jones 'e (2011) göre, sosyal pazarlama uygulamaları alt akım ve üst akım yaklaşımlarıyla gerçekleştirilir. Alt akım, sigarayı bırakmak, obezite, cinsel yollardan bulaşan hastalıklardan korunma, doğum kontrolü gibi konularda insanları bilinçlendirmek amacına dayanmaktadır. Eğitim programları, kamu spotları, iletişim stratejileri ve medya kampanyaları gibi faaliyetlerle insanlar bilgilendirme ve cesaretlendirmeye çalışılır (Potente ve Diğ., 2011). Üst akım ise, toplumsal yaşamı düzenleyici konumunda bulunan; yasa yapıcılar, politikacılar, ticari kuruluşlar gibi çeşitli mekanizmaların sigara ve uyuşturucu kullanımını engelleme/yasaklama benzeri yöntemlerle insanları istenmeyen davranışlardan uzak tutmaya yönelik eylemlerdir (Jones ve Donovan, 2002).

Sosyal pazarlama uygulamalarıyla işletmeler, toplum nezdinde sadece kâr eden birimler olmadıklarını; toplumun ilgi, destek ve beğenisini çeken ve toplumsal fayda yaratan sosyal sorumluluk bilincine sahip yapılar olduklarını da ortaya koyma şansını elde etmişlerdir (Mert, 2012). Aktan'da (2017) sosyal pazarlamayla işletmelerin, rekabetin az veya hiç olmadığı bir ortamda faaliyet gösterdikleri, tüketicilerin ürün ve hizmet satın alırken her zaman para ödemek zorunda olmadıklarına dikkat çekmiştir.

\subsection{Marka İletişimi}

Marka iletişimi, işletmeler tarafından pazarlanan ürünlere ilişkin tüketiciler nezdinde farklılığın tanınmasına katkı sağlayacak bir fikir veya imaj olarak ifade edilebilir (Chinomona, 2016). Şahin, Zehir ve Kitapçı (2011)'leri marka iletişimini, işletmeler tarafından marka farkındalığı yaratmanın yanında firmanın iyi bir üne sahip olması ve bunun devamı için harcanan çabalar olarak betimlemişlerdir.

Marka iletişimi olumlu marka tutumu oluşturulmasında önemli bir role sahiptir (Keller ve Lehmann, 2006). Aynı zamanda tüketicilerle iletişimde ve marka yönetimi faaliyetlerinde marka güveni ve tatmini gibi markaya yönelik pozitif tutum yaratmada temel unsurlardan biridir (Şahin, Zehir ve Kitapç1, 2011). Zehir ve Diğ.'leri (2011) marka iletişimi amacının, yüksek hatırlanma ve farkındalıkla ürünlerin tüketiciler tarafından satın alınmalarının ve müşteri tatmininin optimum düzeyde sağlanması için gerekli olan faaliyetler dizisi olarak ifade etmişlerdir.

Rodriguez, Camero ve Gutierrez (2002) araştırmalarında, marka iletişiminin, tüketicilerin markaların görünümüne ilişkin algıları ve değerlendirmeleri etkileyen bütün iletişim kanallarına başvurduklarını ifade etmişlerdir. Yazarlar, işletmelerin son yıllarda markalarıyla ilgili iletişim yaklaşımlarını değiştirdiklerini belirtmişlerdir. Yeni yaklaşım; işletmelerin tüketiciler için değer ifade edebilecek yaratıcı argümanları kullanmaları sonucunda tüketici sadakati oluşturma ve sonuçta kurumsal karları olumlu 
etkileyebilme esasına dayanmaktadır. Böylece işletmeler, farklılaşmaların yanında birde sosyal bir kurum olarak kabul edilebilirliği görebileceklerdir. Ayrıca tüketicilerle belirtilen amaçlarla kurulan iletişimin, diğer tüketicilerin satın alma niyetlerine etki edebilecek tavsiyelere de dönüşebileceği söylenebilir (Villagra, Lopez ve Monfort, 2015).

Clemente Mediavilla ve Sebastian Morillas'e (2018) göre; yeni tüketicilere ulaşabilmek için farklı iletişim söylemleri kullanmak işletmelerin ana önceliği olmalıdır. Madhavaram, Badrinarayanan ve McDonald (2005)'de marka iletişiminin, markanın pazarlama stratejisinin ana ögesi olmasını gerektiğini belirtmişlerdir.

Dwivedi ve McDonald (2018), marka iletişimiyle ilgili çalışmalarında geleneksel firma görüşleri yerine tüketici bakış açılarının benimsenmesi gerektiğini öne sürmüşlerdir. Araştırmalarında marka iletişiminin; reklam, sponsorluk, sosyal medya ve kurumsal sosyal sorumluluk boyutlarıyla incelenmesi gerektiğini ifade etmişlerdir.

\subsection{Marka Güveni}

Marka güveni, tüketicilerin bir markanın bir işi yapabileceğine olan inançları (Aydın, 2017; Jin ve Lee, 2010) olarak ifade edilebilir. Nawaz ve Usman'a (2011) göre; güven bir işletmenin tüketicilere kaliteli ürünler sunmayı vaat ettiğinde ve sözünü başarıyla yerine getirdiğinde yaratılır.

Yazında marka güveniyle ilgili yapılan çalışmalarda, tüketiciler ile marka arasındaki ilişkinin temelinin markaya olan güvene dayandığ 1 ifade edilmiştir (Chiu, Huang ve Yen, 2010; Papatya, Papatya ve Hamşığlu, 2015, Yang ve Liu, 2018).

Gefen, Karahanna ve Straub'a (2003) göre; marka güveni tüketicilerin algıladıkları belirsizliğin ve bilgi asimetrisinin azaltılmasını sağlar, bu sayede tüketiciler kendilerini daha rahat hisseder. Eğer tüketiciler markanın faydacı ve hedonik değerlerini fark ederse güven daha da artar (Carroll ve Ahuvia, 2006).

Chinomona (2016) çalışmasında, marka yönetimi ve tüketicilerde markaya yönelik pozitif tutum oluşturulmasında marka güveninin birincil öncelikli bütüncül bir element olduğunu öne sürmüştür.

Yazındaki çalışmalarda, marka güveninin sadakat yaratmadaki belirleyici rolü ifade edilmiştir (Menidjel, Benhabib ve Bilgihan, 2017). Bir markaya güvenen tüketiciler, markaya sadık kalmaya, marka adı altında tanıtılan yeni ürün gruplarını daha yüksek fiyatla satın almaya isteklidirler (Mabkhot, Shari ve Salleh, 2017).

Şahin ve Gültekin'de (2017) çalışmalarında, güven duyulan markaya olan tercih eğilimimin işletmelerin pazar paylarının artmasına olanak sağladığını ifade etmişlerdir. Moon, Costello ve Koo da (2017), markanın güvenilirlik ve yetkinliğinin daha yüksek satın almaya yol açabileceği ancak markayla ilgili olumsuz duygular var olduğunda da en büyük zararın marka güveni üzerinde olacağını belirtmişlerdir.

Yavuz ve Ünal'a (2018) göre; marka güveninin bilişsel ve duygusal olmak üzere iki boyutu vardır. Yazarlar bilişsel marka güvenini, tüketicinin markanın yeterliliğine olan inancı olarak ifade etmişlerdir. Tüketici marka hakkında ne kadar fazla bilgi sahibi olabilirse markaya olan güvenin güçleneceği ve bu durumun markanın tercih edilmesine olan katkısını belirtmişlerdir. Duygusal marka güvenini de, tüketicilerin markaya karşı olan ilgilenim düzeyleri olarak tanımlanmıştır.

\subsection{Daha Fazla Ödeme İsteği}

Daha fazla ödeme isteği, tüketiciler için bir ürün veya hizmet satın alımında, kabul edilebilir olan fiyata ödeme yapma eğilimi (Krishna, 1991); aynı kalite ve 
özellikteki diğer markalara oranla tercih ettikleri markalar için daha fazla ödeme yapma isteği (Li, Robson ve Coats, 2013) olarak ifade edilebilir.

O’Cass ve Choy (2008) daha fazla ödeme isteğini, ürün durumunu değerlendirme ve tüketici tutumlarının bir sonucu olarak ifade etmişlerdir. $\mathrm{Li}$, Li ve Kambele'de (2012), bu sonucun tüketici değerlerinin bir kombinasyonu olduğunu belirtmişlerdir. Aynı zamanda, daha fazla ödeme isteğinin satın alma davranışı için olan itici gücüne ve marka sadakatinin belirleyicisi olması konusundaki göreceli önemine işaret etmişlerdir.

Shin ve Diğ.'ne (2017) göre; tüketicilerin daha fazla ödeme istekliliği, bir ürün veya hizmet için ödül fiyatı ödemeye isteğidir. Yazarlar, özellikle insan sağlığı ve çevre gibi hayati derecede önemli alanlarda, tüketicilerin ürünlere daha fazla ödeme yapma özverisini gösterdiklerini ifade etmişlerdir.

Bayraktar (2015), çalışmasında daha fazla ödeme isteğini, tüketicilerin bir ürün alırken alternatifler arasından bir markaya gönüllü olarak gerekenden daha fazlasını ödemeleri olarak tanımlanmıştır. Örneğin, bir tüketicinin Toyota marka bir araba için benzer özelliklerdeki Honda'ya göre \%10 daha fazla ödemesidir. Buna markayla ilişkili "fiyat primleri" denir. Fiyat primi, karşılaştırmaya dahil olan markalara bağlı olarak yüksek veya düşük, pozitif veya negatif olabilir.

Siew, Minor ve Felix'e (2018) göre; tüketiciler sevdikleri markalara daha fazla ödeme yapmaya istek duyarlar. Onlara göre markaları benzersizdir, bu benzersizlik rakip markaların çekicilikleri olsa bile o markalara yönelik bir talepte bulunmalarına engel olmaktadir.

\section{Metodoloji}

$\mathrm{Bu}$ bölümde; araştırmanın modeli, hipotezleri, araştırmanın değişkenleri, örnekleme süreci, veri toplama yöntemi ile geçerlilik ve güvenilirlik analizlerine ilişkin sonuçlara yer verilmiştir.

\subsection{Araştırmanın Modeli ve Hipotezleri}

Yazın taraması sonucunda oluşturulan araştırma modeli Şekil 1'de gösterilmiştir.

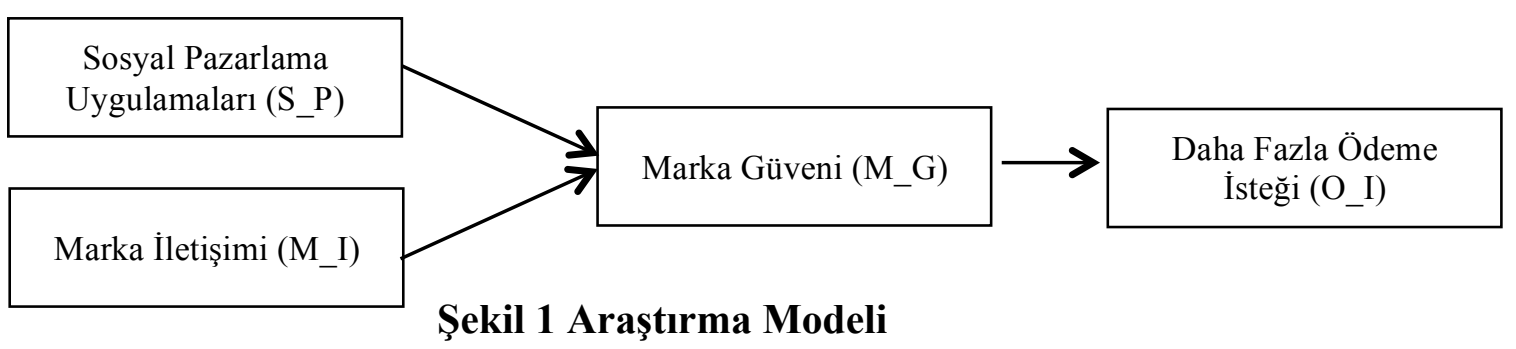

Araştırma hipotezleri aşağıda gösterilmiştir;

$\mathbf{H}_{1}$ : Sosyal pazarlama uygulamaları ile marka güveni arasında anlamlı ve aynı yönlü ilişki vardır.

$\mathbf{H}_{2}$ : Marka iletişimi ile marka güveni arasında anlamlı ve aynı yönlü ilişki vardır. vardir.

$\mathbf{H}_{3}$ : Marka güveni ile daha fazla ödeme isteği arasında anlamlı ve aynı yönlü ilişki

$\mathbf{H}_{4}$ : Sosyal pazarlama uygulamalarının daha fazla ödeme isteği üzerinde marka güveni üzerinden dolaylı etkileri vardır.

$\mathbf{H}_{5}$ : Marka iletişiminin daha fazla ödeme isteği üzerinde marka güveni üzerinden dolaylı etkileri vardır. 


\subsection{Araştırmanın Değişkenleri}

Sosyal pazarlama uygulamaları ölçeği Mert'in (2012) çalışmasından alınmış olup 9 ifade, marka iletişimi ölçeği Zehir ve Diğ.'nin (2011) çalışmasından alınmış olup 6 ifade, marka güveni ölçeği Azizi'nin (2014) çalışmasından alınmış olup 4 ifade ve daha fazla ödeme isteği ölçeği de Li, Robson ve Coates (2013) ile Aydın'ın (2016) çalışmalarından alınmış olup 4 ifadeyle ölçülmüştür.

\section{3. Örnekleme Süreci}

Araştırmanın yapılacağı şampuan sektöründe tüketiciler tarafından bilinen ve tüketicilerde bir karşıllı̆̆ı ve değeri olan sosyal pazarlama uygulamalarını ortaya çıkarmak amacıyla bir odak grup çalışması yapılmıştır. Odak grup çalışması kapsamına 10 akademisyenden oluşan bir grup dahil edilmiştir.

İlk aşamada odak grup çalışmasına alınan tüketicilere, kullandıkları şampuan markaları ve markaların üretici firmalarına yönelik sorular yöneltilmiştir. Elde edilen cevaplar doğrultusunda, ikinci aşamada, üretici firmaların topluma katkı sağlayan sosyal sorumluluk projelerine yönelik sorular sorulmuştur. Deneklerin \%80'ninde “Kazanmak Kafada Başlar" sloganını kullanan Head \& Shoulders markası ve bu markanın; Dünya, Avrupa ve Türkiye Basketbol liginde yaptığı sponsorluklarla gençlere ve spora verdiği destek ön plana çıkmıştır. Dolayısıyla bu araştırmanın evrenini, Ankara'da ikamet eden ve odak grup çalışmasında ön plana çıkan Head \& Shoulders marka şampuanı kullanan tüketiciler oluşturmuştur.

Gürbüz ve Şahin'in (2014) "Farklı Evrenler İçin Kabul Edilebilir Asgari Örneklem Büyüklükleri” isimli tablosunda \%95 güven düzeyinde 250.000 ve daha büyük sayıdaki evrenler için gerekli örneklem büyüklüğü 384 olarak ifade edilmiştir. Bu bilgiye dayanarak bu araştırmada da örneklem büyüklüğü 384 olarak belirlenmiştir.

$\mathrm{Bu}$ çalışmada; zaman, maliyet ve ulaşma güçlükleri nedeniyle kolayda örnekleme tekniği kullanılmıştır ve veriler anlık olarak toplanmıştır.

\subsection{Veri Toplama Yöntemi}

Araştırma verileri anketle toplanmıştır. Anket iki bölümden ve 29 ifadeden oluşturulmuştur. Birinci bölümde katılımcıların demografik bilgilerini ölçen 5 ifadeye, ikinci bölümde de araştırmanın değişkenleri ölçen 23 ifadeye yer verilmiştir. Katılımcılardan, yargılara, 5'li Likert Ölçeği kullanarak (1=Kesinlikle Katılmıyorum, 2= Katılmıyorum, 3=Kararsızım, 4=Katılıyorum, 5=Kesinlikle Katıliyorum) cevap verilmesi istenmiştir.

Anket uygulaması 1 Haziran - 30 Temmuz 2017 tarihleri arasında gerçekleştirilmiş ve kullanılabilir 384 veri elde edilmiştir.

\subsection{Geçerlilik ve Güvenilirlik Analizleri}

Ölçeklerin yapı geçerliliği faktör analiziyle test edilmiştir. AMOS 22 programıyla tüm ölçekler için tek faktörlü doğrulayıcı faktör analizi yapılmıştır.

Ölçüm modellerinin ürettikleri uyum değerleri istenen sinırlarda gerçekleşmediğinden AMOS programının önerdiği modifikasyon indekslerine dayanarak ölçeklerde gerekli modifikasyonlar yapılmıştır. Modifikasyonlarda; sosyal pazarlama ölçeğinden 2 ifade ve marka iletişimi ölçeğinden 1 ifade olmak üzere toplam 
3 ifade ölçeklerden çıkartılmıştır. Ayrıca; sosyal pazarlama ölçeğinin 1 ve 2 numaralı ifadelerinin hata terimleri arasında kovaryans bağıntısı yapılmıştır.

Yapılan modifikasyonlar sonucu ölçüm modellerinin uyum değerleri istenen sınırlarda gözlemlendiğinden tüm değişkenlerin tek faktörlü yapıları doğrulanmıştır. Tablo 1'de ölçeklerin; faktör yükleri, ortalama açılanan varyans (AVE=Average Variance Extracted), her bir yapıya ilişkin birleşik güvenilirlik ( $\mathrm{CR}=$ Composite Reliabilty) değerleri ve Cronbach Alfa katsayıları gösterilmiştir.

Tablo 1 Ölçüm Modeli Sonuçları

\begin{tabular}{|c|c|c|c|c|c|c|}
\hline 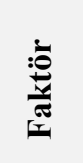 &.$\stackrel{\mathscr{J}}{\leftrightarrows}$ & 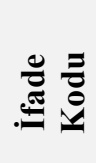 & 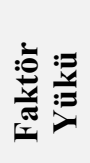 & $\sum_{4}^{1-1}$ & $\tilde{U}$ & 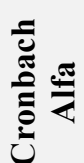 \\
\hline \multirow{7}{*}{ 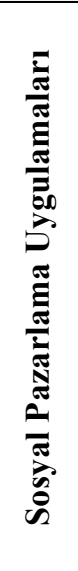 } & $\begin{array}{l}\text { Fiyat ve kalite benzer olduğunda, sosyal projelere } \\
\text { destek veren işletmenin ürünlerini tercih ederim. }\end{array}$ & SP1 & 0,56 & \multirow{7}{*}{0,56} & \multirow{7}{*}{0,89} & \multirow{7}{*}{0,89} \\
\hline & $\begin{array}{l}\text { Sosyal içerikli projeler gerçekleştiren işletmelerden } \\
\text { ürün/hizmet alarak destek olmaya çalışırım. }\end{array}$ & SP2 & 0,63 & & & \\
\hline & $\begin{array}{l}\text { Firmaların sosyal projeler } \\
\text { toplumsal değil kâr odaklıdır. }\end{array}$ & SP3 & 0,82 & & & \\
\hline & $\begin{array}{l}\text { Satın alma kararımda firmanın sosyal fayda } \\
\text { yaratması tercihlerimi etkiler. }\end{array}$ & SP4 & 0,91 & & & \\
\hline & $\begin{array}{l}\text { İşletmelerin sosyal fayda yaratabileceklerine } \\
\text { inaniyorum. }\end{array}$ & SP5 & 0,88 & & & \\
\hline & $\begin{array}{l}\text { Bir sivil toplum kuruluşu ile birlikte çalışmak } \\
\text { kampanyanın etkinliğini arttırır. }\end{array}$ & SP6 & 0,87 & & & \\
\hline & $\begin{array}{l}\text { Toplumsal fayda yaratan bir ürüne aynı kalitedeki } \\
\text { başka bir üründen daha fazla bedel ödeyebilirim. }\end{array}$ & SP7 & 0,41 & & & \\
\hline \multirow{5}{*}{ 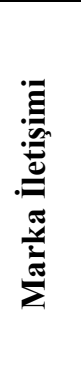 } & $\begin{array}{l}\text { Bu markanın reklamlarına ve tanıtımlarına olumlu } \\
\text { yaklaşırım. }\end{array}$ & MI1 & 0,80 & \multirow{5}{*}{0,55} & \multirow{5}{*}{0,86} & \multirow{5}{*}{0,85} \\
\hline & $\begin{array}{l}\text { Bu markanın reklam ve tanıtımlarına karşı olumlu } \\
\text { hissederim. }\end{array}$ & MI2 & 0,83 & & & \\
\hline & Bu markanın reklam ve tanıtımları iyidir. & MI3 & 0,76 & & & \\
\hline & $\begin{array}{l}\text { Bu markanın reklam ve tanıtımları iyi iş } \\
\text { çıkarmaktadır. }\end{array}$ & MI4 & 0,74 & & & \\
\hline & Bu markanın reklam ve tanıtımlarını beğenirim. & MI6 & 0,56 & & & \\
\hline \multirow{4}{*}{ 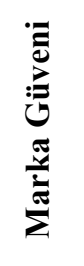 } & Bu marka beklentilerimi karşılar. & MG1 & 0,92 & \multirow{4}{*}{0,74} & \multirow{4}{*}{0,92} & \multirow{4}{*}{0,91} \\
\hline & Bu marka beni hayal kırıklığına uğratmaz. & MG2 & 0,81 & & & \\
\hline & $\mathrm{Bu}$ marka memnuniyeti garanti eder. & MG3 & 0,88 & & & \\
\hline & Bu marka problemlerimi çözer. & MG4 & 0,83 & & & \\
\hline \multirow{4}{*}{ 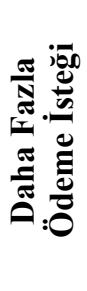 } & Bu markaya daha fazla ödeme yapmak isterim. & OI1 & 0,85 & \multirow{4}{*}{0,63} & \multirow{4}{*}{0,87} & \multirow{4}{*}{0,87} \\
\hline & Fiyatları artsa da yine bu markayı alırım. & $\mathrm{OI} 2$ & 0,65 & & & \\
\hline & $\begin{array}{l}\text { Fiyatları birbirine yakın olsa da yine bu markanın } \\
\text { ürünleri tercih ederim. }\end{array}$ & OI3 & 0,90 & & & \\
\hline & $\begin{array}{l}\text { Rakip markalara geçmeden önce bu markanın } \\
\text { fiyatının belirgin şekilde artması gerek. }\end{array}$ & OI4 & 0,75 & & & \\
\hline
\end{tabular}

Fornell ve Larcker (1981) yakınsak geçerliliğin sağlanabilmesi için üç koşulun var olması gerektiğini ifade etmişlerdir. Söz konusu koşullar; her bir maddenin faktör yük 
değerinin 0,50'den büyük olması, ortalama açıklanan varyans değerinin (AVE) 0,50'ye eşit veya büyük olması ve birleşik güvenilirlik (CR) alfa katsayısının da 0,70 veya üstünde olmasıdır. Tablo 1 'deki değerler incelendiğinde faktör yük değerlerinin 0,41 ile 0,92 arasında, AVE değerlerinin 0,55 ile 0,74 arasında ve CR değerlerinin de 0,86 ile 0,92 değerleri arasında olduğu görülmektedir. $\mathrm{Bu}$ bulgulara dayanarak yakınsak geçerliliğin sağlandığı ifade edilebilir.

Tablodaki Cronbach Alfa katsayıları da incelendiğinde, katsayıların 0,85 ile 0,91 arasında olduğu görülmektedir. Bu bulguya dayanarak ölçeklerin yüksek seviyede güvenilir olduğu söylenebilir.

\section{Bulgular}

$\mathrm{Bu}$ bölümde yapılan analizler sonucunda ulaşılan sonuçlar derlenmiştir.

\subsection{Katılımcıların Demografik Özellikleri}

Tablo 2'de katılımcıların demografik özelliklerine yer verilmiştir.

Tablo 2 Katılımcıların Demografik Özellikleri

\begin{tabular}{|c|c|c|c|c|c|c|c|}
\hline \multicolumn{2}{|c|}{ Özellik } & \multirow{2}{*}{$\begin{array}{c}\text { Sıklık } \\
126 \\
\end{array}$} & \multirow{2}{*}{$\begin{array}{c}\% \\
32,8 \\
\end{array}$} & \multicolumn{2}{|c|}{ Özellik } & \multirow{2}{*}{$\begin{array}{c}\text { Sıklık } \\
47 \\
\end{array}$} & \multirow{2}{*}{$\begin{array}{c}\mathbf{\%} \\
12,2\end{array}$} \\
\hline \multirow{3}{*}{ Cinsiyet } & Kadın & & & \multirow{6}{*}{$\begin{array}{l}\text { Eğitim } \\
\text { Durumu }\end{array}$} & Lise ve alt1 & & \\
\hline & Erkek & 258 & 67,2 & & Üniversite & 266 & 69,3 \\
\hline & Toplam & 384 & 100,0 & & & & 185 \\
\hline \multirow{3}{*}{$\begin{array}{l}\text { Medeni } \\
\text { Durum }\end{array}$} & Evli & 74 & 19,3 & & Lisansustu & 11 & 18,3 \\
\hline & Bekâr & 310 & 80,7 & & \multirow{2}{*}{ Toplam } & \multirow{2}{*}{384} & \multirow{2}{*}{100,0} \\
\hline & Toplam & 384 & 100,0 & & & & \\
\hline \multirow{5}{*}{ Yaş } & $20-30$ & 202 & 52,6 & \multirow{5}{*}{ Gelir } & $1500-3000$ & 170 & 44,3 \\
\hline & $31-40$ & 104 & 27,1 & & $3001-4500$ & 115 & 29,9 \\
\hline & $41-50$ & 65 & 16,9 & & $4501-6000$ & 42 & 10,9 \\
\hline & 51 ve üstü & 13 & 3,4 & & 6001 ve üstü & 57 & 14,8 \\
\hline & Toplam & 384 & 100,0 & & Toplam & 384 & 100,0 \\
\hline
\end{tabular}

Katılımc1ların; \%32,8'i kadın ( $\mathrm{N}=126)$; \%67,2'si erkektir $(\mathrm{N}=258)$. \%19,3'ü evli $(\mathrm{N}=74)$; \%80,7'si bekârdır ( $\mathrm{N}=310)$. \%52,6'sı 20-30 yaş aralığında $(\mathrm{N}=202) ; \% 69,3$ 'ü üniversite mezunu $(\mathrm{N}=266)$ ve \%44,3'ü 1500-3000 TL gelir aralığındadır $(\mathrm{N}=170)$.

\subsection{Korelasyon Bulguları ve tanımlayıcı İstatistikler}

Tablo 3'te korelasyon bulguları ve tanımlayıcı istatistikler sunulmuştur.

Tablo 3 Korelasyon Bulguları ve Tanımlayıcı İstatistikler

\begin{tabular}{|c|c|c|c|c|c|c|}
\hline & Ort. & $\begin{array}{c}\text { Standart } \\
\text { Sapma }\end{array}$ & $\begin{array}{c}\text { Sosyal } \\
\text { Pazarlama } \\
\text { Uygulamaları }\end{array}$ & $\begin{array}{c}\text { Marka } \\
\text { İletişimi }\end{array}$ & $\begin{array}{c}\text { Marka } \\
\text { Güveni }\end{array}$ & $\begin{array}{c}\text { Daha } \\
\text { Fazla } \\
\text { Ödeme } \\
\text { İsteği }\end{array}$ \\
\hline $\begin{array}{c}\text { Sosyal Pazarlama } \\
\text { Uygulamaları }\end{array}$ & 3,58 & 0,76 & 1 & $0,79^{* *}$ & $0,75^{* *}$ & $0,74^{* *}$ \\
\hline Marka İletişimi & 3,90 & 0,74 & $0,79^{* *}$ & 1 & $0,74^{* *}$ & $0,66^{* *}$ \\
\hline Marka Güveni & 3,84 & 0,91 & $0,75^{* *}$ & $0,74^{* *}$ & 1 & $0,76^{* *}$ \\
\hline $\begin{array}{c}\text { Daha Fazla } \\
\text { Oddeme İsteği }\end{array}$ & 3,12 & 0,98 & $0,74^{* *}$ & $0,66^{* *}$ & $0,76^{* *}$ & 1 \\
\hline
\end{tabular}

${ }^{* *}<0,01(N=384)$ 
Katılımcıların algıları, en yüksek ortalama ile marka iletişimi değişkeninde $($ Ort. $=3,90)$; en düşük ortalama ise daha fazla ödeme isteği değişkeninde $($ Ort. $=3,12)$ gerçekleşmiştir. Bu sonuçlara göre, deneklerin araştırma değişkenlerini ölçen algılara katılım oranlarının genel olarak ortalama değerden yüksek olarak gerçekleştiği söylenebilir.

Korelasyon bulguları da incelendiğinde, marka iletişimi ile daha fazla ödeme isteği değişkenleri arasında orta seviyede, diğer değişkenler arasındaki ilişkilerin yüksek seviyede ve pozitif yönlü olduğu görülmektedir.

\subsection{Yapısal Eşitlik Modeli}

Şekil 2'de hipotezlerin testi için kullanılan yapısal eşitlik modeli gösterilmiştir.

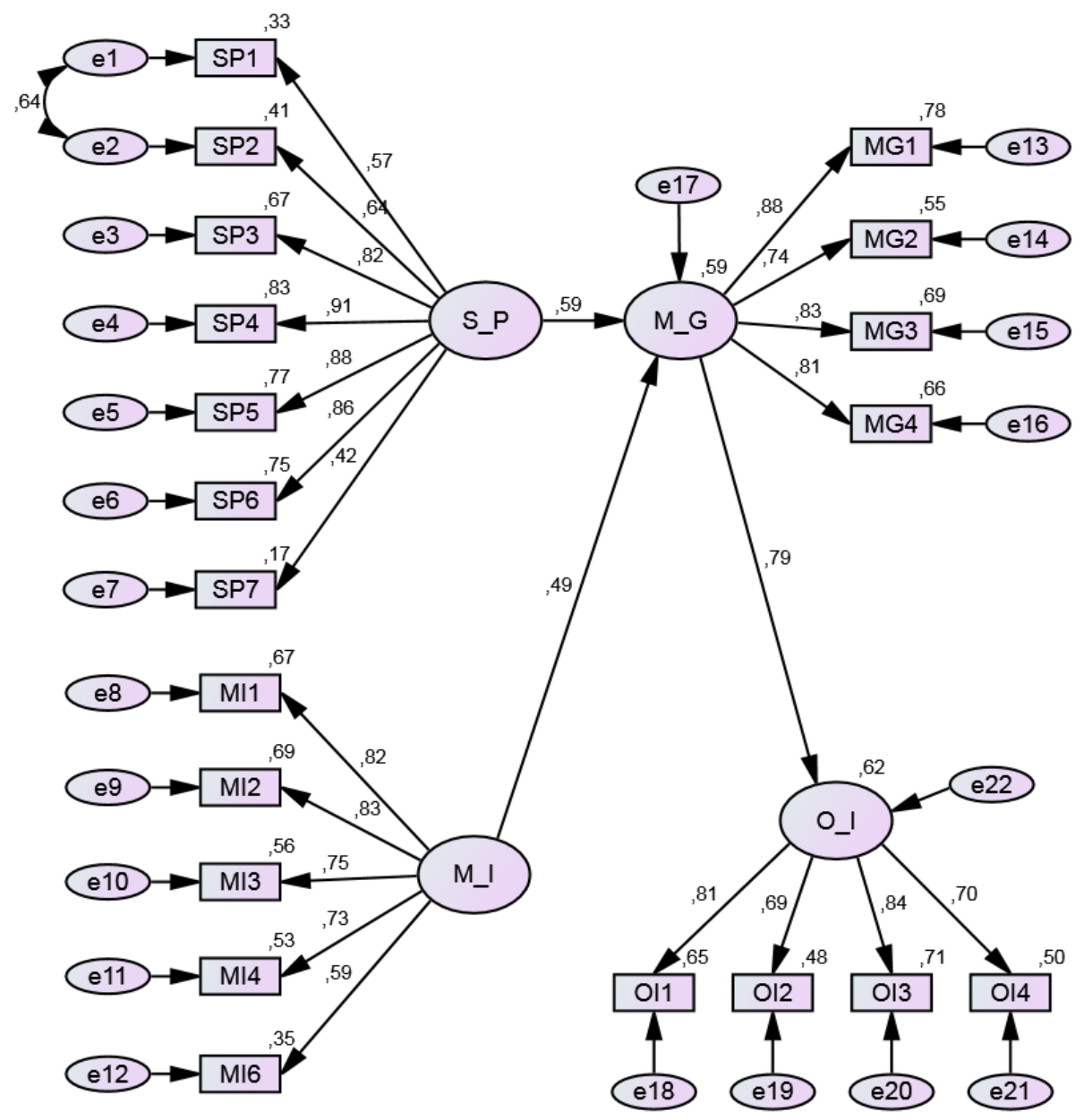

Şekil 2 Yapısal Eşitlik Modeli

Tablo 4'te yapısal modelin katsayılarına yer verilmiştir.

Tablo 4 Yapısal Eşitlik Modeli Katsayıları

\begin{tabular}{|c|c|c|c|c|c|}
\hline Değişkenler & $\begin{array}{c}\text { Standardize } \\
\boldsymbol{\beta}\end{array}$ & $\begin{array}{c}\text { Standart } \\
\text { Hata }\end{array}$ & $\begin{array}{c}\text { Kritik } \\
\text { Oran }\end{array}$ & $\mathbf{p}$ & $\mathbf{R}^{\mathbf{2}}$ \\
\hline Sosyal Pazarlama Uygulamaları - Marka Güveni & 0,59 & 0,045 & 10,599 & $* * *$ & \multirow{2}{*}{0,59} \\
\hline Marka İletişimi - Marka Güveni & 0,49 & 0,071 & 9,693 & $* * *$ & \\
\hline Marka Güveni - Daha Fazla Ödeme İsteği & 0,79 & 0,067 & 14,585 & $* * *$ & 0,62 \\
\hline
\end{tabular}


Tablodaki değerler incelendiğinde; sosyal pazarlama uygulamalarının marka güvenini $(\beta=0,59 ; p<0,01)$, marka iletişiminin marka güvenini $(\beta=0,49 ; p<0,01)$ ve marka güveninin daha fazla ödeme isteğini $(\beta=0,79 ; p<0,01)$ etkilediği görülmektedir.

Yapısal eşitlik modeliyle dolaylı etkilerde hesaplanmıştır. Sosyal pazarlama uygulamalarının marka güveni üzerinden daha fazla ödeme isteği $(\beta=0,47 ; p<0,01)$ ve marka iletişiminin de marka güveni üzerinden daha fazla ödeme isteği $(\beta=0,39 ; p<0,01)$ üzerinde dolaylı etkileri olduğu tespit edilmiştir.

Araştırma sonuçları tüm hipotezlerin desteklendiği ortaya çıkarmıştır. $\mathrm{R}^{2}$ değerleri incelendiğinde; marka güveninin $\% 59$, daha fazla ödeme isteğinin de $\% 62$ oranında açıklandığı tespit edilmiştir.

\section{Sonuç ve Tartışma}

Uygulamamın yapıldığı şampuan sektörü kozmetik sektörü içinde ciddi bir pazar payına sahiptir ve yerel markalar yanında da dünya devi markalar arasında da kıyasıya bir rekabet yaşanmaktadır. Pazarda çok fazla sayıda ve çok farklı çeşitlerde şampuan ürünleri mevcuttur. $\mathrm{Bu}$ ürün çokluğunda tüketicileri tekrarlanan satın almalara ikna etmenin, firmalar açısından son derece güç olduğu ifade edilebilir. Söz konusu sektördeki ürün özelliklerinin ve fiyat aralıklarının çok farklı olmadığı da göz önüne alındığında, yaşanan rekabetin şiddeti tahmin edilebilir.

Belirtilen koşullar altında, markaların tercih edilme ihtimallerini arttırabilmeleri için, son yıllarda tüketicilerin nezdinde çok daha fazla anlam ifade eden, toplumsal fayda yaratan sosyal içerikli uygulamalarla, tüketicilerle kuracakları iletişimin ne kadar önemli olduğu konusunda bir öngörüde bulunulabilir. Markaların, ortaya koydukları toplumsal faydalarla desteklenen tutundurma aktiviteleriyle, kendilerini farklı bir yere konumlandırabilecekleri yönünde bir değerlendirme yapılabilir.

Araştırma bulguları, sosyal pazarlama uygulamaları ve marka iletişim çabalarının marka güveni üzerinde, marka güveninin de daha fazla ödeme isteği üzerindeki etkilerini ortaya çıkarmıştır. Aynı zamanda sosyal pazarlama uygulamaları ve marka iletişiminin daha fazla ödeme isteği üzerinde dolaylı etkilerinin de olduğu tespit edilmiştir.

$\mathrm{Bu}$ bulgulara dayanarak tüketicilerin; eğitim, sağlik, spor vb. faaliyetlere sağladıkları katkılarla toplumsal fayda sağlayan ve reklam ve benzeri tutundurma faaliyetleriyle, tüketiciler için değer ifade eden iletişim çabalarıyla, markaya ilişsin güven duygusunun oluşturulabileceği söylenebilir. Markayla ilgili beklentileri karşılanan tüketicilerin, gerektiğinde de ürün için daha fazla ödeme yapabilecekleri yönünde bir öngörüde bulunulabilir.

Araştırmanın en büyük kısıtı uygulamanın tek il ve tek sektörde yapılmış olmasıdır. Örnekleme tekniği de diğer bir kısıt olarak ifade edilebilir. Gelecek araştırmalarda farklı sektörlerden toplanacak verilerle çalışmanın tekrarlanmasının uygun olacağ 


\section{KAYNAKLAR}

Aktan, M., (2017). "Sigara Paketlerinde Bulunan Birleşik Sağlık Uyarılarının Etkinliğinin Sosyal Pazarlama Açısından Değerlendirilmesi”, Business and Economics Research Journal, Vol. 8, No. 3, 555-573.

Andreasen, A. R., (1994). "Social marketing: its definition and domain", Journal of Public Policy and Marketing, 13, 108-114.

Aydın, G. ve Koç, E., (2016). "Social marketing analysis of attitude toward compulsory earthquake insurance in Turkey", Yönetim ve Ekonomi Dergisi, Cilt. 23, Sayı. 2.

Aydın, H., (2017). "Marka güveni, farkındalığı ve benlik imaj uyumunun marka bağlılığına etkisinde marka aşkının aracılık rolü’, Ege Akademik Bakış, Cilt. 17, Say1. 2, 281-294.

Azizi, S., (2014). "A model of factors affecting foreign brand trust", Journal of Competitiveness, Vol. 6, No. 3, 20-31.

Bayraktar, A., (2015). "Are consumers really willing to pay more for favorable brand associations? The moderating role of product value and product risk level", Ege Akademik Bakış, Cilt. 15, Sayı. 4, 565-575.

Beerli-Palacio, A., Martin-Santana, J., (2015). "How to increase blood donation by social marketing" International Review of Public and Nonprofit Marketing doi: 10.1007/s12208-015-0133-8.

Carroll, B.A., Ahuvia, A., (2006). "Some antecedents and outcomes of brand love", Marketing Letters, Vol. 17, No. 2, 79-89.

Celemente Mediavilla, J., Sebastian Morillas, A., (2018). "New discourses in brand communication in Spain: Adaptation vs. renewal of target audience", Communication Society, 31 (2), 25-38.

Chinomona, R., (2016). "Brand communication, brand image and brand trust as antecedents of brand loyalty in Gauteng Province of South Africa" African Journal of Economic and Management Studies, Vol. 7, No. 1, 124-139

Chiu, C. M., Huang, H. Y., Yen, C. H., (2010). "Antecedents of online trust in online auctions", Electronic Commerce Research and Application, Vol. 9, No. 2, 148159.

Dwivedi, A., McDonald, R., (2018). "Building brand authenticity in fast-moving consumer goods via consumer perceptions of brand marketing communications", European Journal of Marketing, Vol. 52, No. 7/8, 1387-1471.

Erol, F., (2017). "Dijital dünyanın sosyal uçurumları kapamadaki rolü: sosyal medya ve sosyal pazarlama ilişkisi üzerine bir inceleme", Gümüşhane Üniversitesi Sosyal Bilimler Dergisi, Cilt. 8, Say1. 21, 33-48.

Fornell, C., Larcker, D.F., (1981). "Evaluating structural equation models with unobservable variables and measurement error", Journal of Marketing Research, $48,39-50$.

Gefen, D., Karahanna, E., Straub, D. W., (2003). "Trust and TAM in online shopping: an integrated model”, MIS Quarterly, Vol. 27, No. 1, 51-90. 
Gürbüz, S. ve Şahin, F., (2014). Sosyal Bilimlerde Araştırma Yöntemleri Felsefe Yöntem - Analiz, Seçkin Yayınevi, Ankara.

Hoek, J., Jones, S. C., (2011). "Regulation, public health and social marketing: a behaviour change trinity", Journal of Social Marketing, Vol. 1, No. 1, 32-44.

Jin, S. A. A., Lee, K. M., (2010). "The influence of regulatory fit and interactivity on brand satistaction and trust in e-health marketing inside $3 \mathrm{~d}$ virtual worlds (second life)", Cyberpsychology, Behavior, And Social Networking, 13 (6), 673-680.

Jones, S. C., Donovan, R. J., (2002). "Self-regulation of alcohol advertising: is it working for Australia?", Journal of Public Affairs, Vol. 2, No. 3, 153-165.

Keller, K. L., Lehmann, D. R., (2006). "Brands and branding: research findings and future priorities", Marketing Science, Vol. 25, No. 6, 740-759.

Kotler, P., Andreasen, A., (1996). Strategic marketing for non profit marketing. Englewood Cliffs: Prentice-Hall.

Krishna, A., (1991). "Effect of dealing patterns on consumer perceptions of deal frequency and willingness to pay", Journal of Marketing Research, 441-451.

Li, G., Li, G., Kambele, Z., (2012). "Luxury fashion brand consumers in China: perceived value, fashion lifestyle, and willingness to pay", Journal of Business Research, Vol. 65, No. 10, 1516-1522.

Li, N., Robson, A., Coates, N., (2013). "Chinese consumers' purchasing: impact of value and affect", Journal of Fashion Marketing and Management, Vol. 17, No. 4, 486-508.

Luk, S. T., Yşp, L. S.x (2008). "The moderator effect of monetary sales promotion on the relationship between brand trust and purchase behaviour", Journal of Brand Management, 15 (6), 452-464.

Mabkhot, H. A., Sahari, H., Salleh, S., (2017). "The influence of brand image and brand personality on brand loyalty, mediating by brand trust: an empirical study", Jurnal Pengurusan, 50, 1-18.

Madhavaram, S., Badrinarayanan, V., McDonald, R. E., (2005). "Integrated marketing communication (IMC) and brand identity as critical components of brand equity strategy: a conceptual framework and research propositions", Journal of Advertising, Vol. 34, No. 4, 69-80.

Menidjel, C., Benhabib, A., Bilgihan, A., (2017). "Examining the moderating role of personality traits in the relationship between brand trust and brand loyalty", Journal of Product and Brand Management, 26/6, 631-649.

Mert, G., (2012). "Sosyal pazarlama uygulamalarının tüketici davranışı ve firma performans1 üzerinet etkileri: teori ve bir uygulama", Organizasyon ve Yönetim Bilimleri Dergisi, Cilt. 4, Sayı. 1, 117-129.

Moon, S. J., Costello, J. P., Koo, D. M., (2017). "The impact of consumer confusion from eco-labels on negative WOM, distrust, and dissatisfaction", International Journal of Advertising Vol. 36, No. 2, 246-271. 
Nawaz, N., Usman, A., (2011). "What makes customers brand loyal: A study on telecommunication sector of Pakistan", International Journal of Business and Social Science, 2 (14), 213-221.

O'Cass, A., Choy, E., (2008). “Studying Chinese generation Y consumers' involvement in fashion clothing and perceived brand status2, Journal of Product \& Brand Management, Vol. 17, No. 5, 341-352.

Papatya, N., Papatya, G. ve Hamşığlu, A. B., (2015). "Sürdürülebilir rekabet yönetiminde marka değeri ve marka güveni: Süleyman Demirel Üniversitesinde bir uygulama", Süleyman Demirel Üniversitesi İktisadi ve İdari Bilimler Fakültesi Dergisi, Cilt. 20, Say1. 3, 35-54.

Potente, S., McIver, J., Anderson, C., Coppa, K., (2011). "It's a beautiful day for cancer": an innovative communication strategy to engage youth in skin cancer prevention", Social Marketing Quarterly, 17, 86-105.

Rogdiguez, S., Camero, C, Gutierrez, J., (2002). "Loyalty and value in the consumer's relationship. An application to the case of financial service", Granada: Universidad de Valladolid. Ponencia publicade en las memorias del XIV Encuentro de Profesores Universitarios de Marketing, 2-15.

Shin, Y. H., Moon, H., Jung, S. E., Severt, K., (2017). "The effect of environmental values and attitudes on consumer willingness to pay more for organic menus: A value-attitude-behavior approach", Journal of Hospitality and Tourism Management, 33, 113-121.

Siew, S. W, Minor, M. S., Felix, R., (2018). "The influence of perceived strength of brand origin on willingness to pay more for luxury goods", Journal of Brand Management, https://doi.org/10.1057/s41262-018-0114-4.

Şahin, A., Zehir, C. ve Kitapçi, H., (2011). "The effects of brand experiences, trust and satisfaction on building brand loyalty; an empricial research on global brands", The $7^{\text {th }}$ International Strategic Management Conference, Paris.

Şahin, E. ve Gültekin, C., (2017). "Markaya duyulan güven ve etnosentrik eğilimlerin marka sadakatine etkisi: bir marka örneği”, Süleyman Demirel Üniversitesi İktisadi ve İdari Bilimler Fakültesi Dergisi, Cilt. 22, Say1. 4, 993-1012.

Uptown, D., Thirlaway, K., (2014). Promoting healthy behavior: A practical guide. Routledge.

Villagra, N., Lopez, B., Monfort, A., (2015). "The management of intangibles and the corparet brand: has someting changed in the relationship between companies and society?" Revista Latina de Commicacion Social, 70, 793-812.

Wasan, P. G., Tripathi, G., (2014). "Revisiting social marketing mix: a socio-cultural perspective",Journal of Services Research, Vol. 14, No. 2, 127-144.

Weinreich, N. K., (2007). "What is social marketing?”, USA: Weinreich Communications.

Yang, Y. C., Liu, S. W., (2018). "Links between switching costs, brand trust, and customer loyalty in mobile phone services", The International Journal of Organizational Innovation, Vol. 10, No. 4, 315-326. 
Yavuz, E. ve Ünal, S., (2018). "Bilişsel ve marka güveninin satın alma davranış1 üzerindeki etkisi: Erzurum ilinde bir araştırma", Atatürk Üniversitesi İktisadi ve İdari Bilimler Dergisi, Cilt. 32, Say1. 2, 247-266.

Zehir, C., Şahin, A., Kitapçı, H. ve Özşahin, M., (2011). “The effects of brand communication and service quality in building brand loyalty through brand trust; the empirical research on global brands", The $7^{\text {th }}$ International Strategic Management Conference, Paris. 
E. Yıldız 10/3 (2018) 471-487

\title{
The Effects of Social Marketing Practices and Brand Communication on Brand Trust and Willingness to Pay More: A Research on the Head \& Shoulders Brand
}

\author{
Erkan YILDIZ \\ Başkent University \\ Kazan Vocational School \\ Ankara, Turkey \\ orcid.org/0000-0002-4398-5378 \\ eryildiz@gmail.com.tr
}

\section{Extensive Summary}

\section{Introduction}

In this study, a survey based on the shampoo sector was carried out to research the effects of brand's social marketing practices and brand communication skills on the trust to the brand and the consumers' willingness to pay more.

\section{Methodology}

\section{Models and Hypotheses of Research}

The research model created as a result of the literature review is shown in Figure 1.

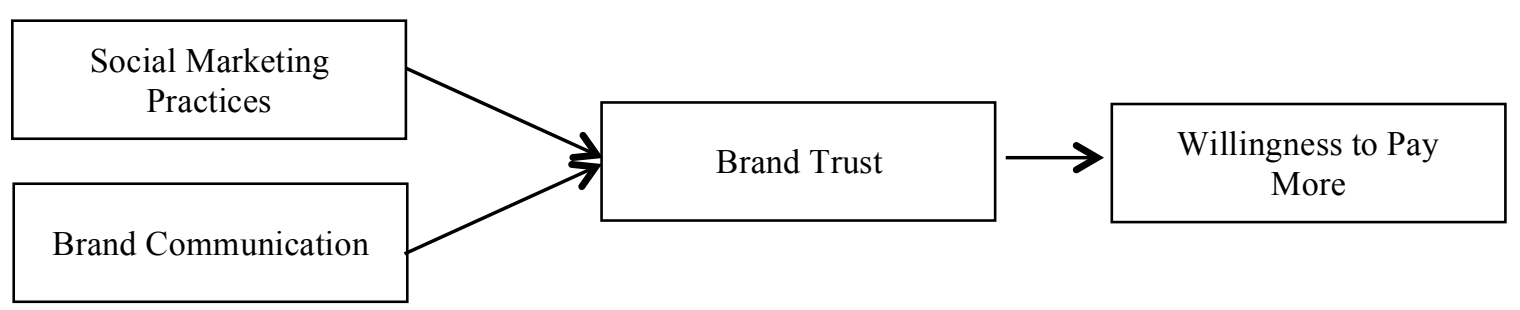

Figure 1 Research Model

Research hypotheses are shown below;

$\mathbf{H}_{1}$ : There is a meaningful and similar relationship between social marketing practices and brand trust.

$\mathbf{H}_{2}$ : There is a meaningful and similar relationship between brand communication and brand trust.

$\mathbf{H}_{3}$ : There is a meaningful and similar relationship between brand trust and willingness to pay more.

$\mathbf{H}_{4}$ : Social marketing practices have indirect effects on willingness to pay more over the brand trust. brand trust.

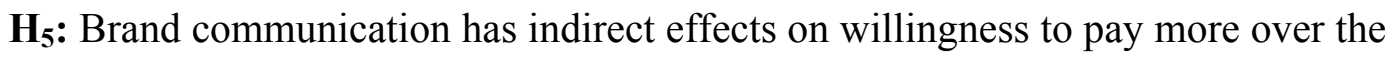




\section{Research Variables}

The social marketing practices scale was taken from the study of Mert's (2012) and measured with 9 expressions; brand communication scale was taken from the study of Zehir et al. (2011) and measured with 6 expressions; brand trust scale was taken from the study of Azizi (2014) and measured with 4 expressions; willingness to pay more scale was taken from the study Li, Robson and Coates (2013) and Aydin (2016) and measured with 4 expressions.

\section{Sampling Process}

During the process of determining the population and sample, a focus group study was carried out with a group of 10 academicians. At the first stage, they were asked about the shampoo brands they used and the manufacturers of the brands. In the direction of the answers obtained, in the second stage of the tests, they were asked about the social responsibility projects of the producer companies contributing to the society. According to the answers of $80 \%$ of the attenders, The Head \& Sholders brand which uses the slogan "to win starts in the head" came to the fore with sponsorships in World, Europe and Turkey Basketball League and the support they give to youth and sport. Therefore, the population of this research was the consumers who live in Ankara and use the Head \& Sholders brand shampoo.

In this study; due to time, cost and difficulties of access, convenience sampling technique was used and data were collected instantaneously. The survey was carried out between June 1 to July 30, 2017 and available 384 data were obtained.

\section{Validity and Reliability Analyzes}

The construct validity of the scales was tested by factor analysis. Single factor confirmatory factor analysis was performed for all scales with AMOS 22 program.

Since the adaptation values produced by the measurement models are not within the acceptable limits, the necessary modifications have been made in the scales based on the modification indexes proposed by the AMOS program. In the modification; 2 expressions were taken from social marketing practices scale and 1 expression was taken from brand communication scale. Also; the covariance relation was made between the error terms of expressions 1 and 2 of the social marketing practices scale. Since the compliance values of the modified measurement model were observed at the acceptable limits, single-factor structures of all variables were verified.

The Cronbach's alpha coefficients of the scales were between 0.85 and 0.91 . Based on this finding, it can be said that the scales are reliable at a high level.

\section{Findings}

\section{Structural Equation Model}

The hypotheses of the research were tested by structural equation modeling. According to the results of the structural model; it was found that social marketing applications affect the brand $\operatorname{trust}(\beta=0.59, \mathrm{p}<0.01)$, brand communication affects the brand trust $(\beta=0.49, \mathrm{p}<0.01)$ and brand trust affects the willingness to pay more directly $(\beta=0.79, \mathrm{p}<0.01)$. 
In addition, social marketing practices affect the willingness to pay more over the brand trust $(\beta=0.47, p<0.01)$ and brand communication affects the willingness to pay more over the brand trust indirectly $(\beta=0.39, \mathrm{p}<0.01)$.

The research results show that all hypotheses are supported. When the $\mathrm{R}^{2}$ values are examined; brand trust was found to be $59 \%$, and willingness to pay more was reported at $62 \%$.

\section{Conclusion and Discussion}

The shampoo sector in which the study is applied has a serious market share within the cosmetics sector and there is also a fierce competition among the world famous brands as well as local brands. There are a large number of shampoo products on the market and in many different varieties. It can be said that it is extremely difficult for companies to convince consumers for repetitive purchases in this competitive market. Given the fact that product characteristics and price ranges in the sector are not very different, the intensity of the competition can be predicted.

Under the stated conditions, it can be said that companies should pay more attention to the socially beneficial applications percieved more meaningful in recent years and to communication with the consumers to increase the likelihood of being preferred. An assessment can be made that brands can position themselves in different places with the promotional activities supported by the social benefits they provide.

Based on these findings, it can be said that brand trust can be developed by means of the contributions they make to education, health, sports etc., by means of advertising and similar promotional activities and effective communication with consumers. A prediction can be made that the consumers who are met the expectations about the brand can pay more for the product if necessary. 